\title{
The particularities specific to the manufacture of nanopowders used in the industrial field
}

\author{
Ghe Samoilescu ${ }^{1}$, A R Bordianu ${ }^{2}$, E A Patroi ${ }^{3}$ and D Patroi ${ }^{3}$ \\ ${ }^{1}$ Naval Academy „Mircea cel Bătrân”, Constanta, Romania \\ ${ }^{2}$ University Politehnica of Bucharest, Bucharest, Romania \\ ${ }^{3}$ INCDIE ICPE-CA Bucharest, Romania
}

E-mail: samoilescugheorghe@yahoo.com

\begin{abstract}
The paper presents the particularities of the manufacture of nanopowders that can be used in industry by conducting a study of the magnetic properties of nanocomposite materials. The research was carried out within the INCDIE ICPE-CA in collaboration with the Naval Academy in Constanța and with the Polytechnic University of Bucharest. Depending on the mechanical, electrical and magnetic characteristics of the nanoparticles, their area of application is analyzed. The paper presents methods of chemical synthesis of magnetic nanoparticles and their importance due to their homogeneity, size control and particle distribution. Many magnetic nanoparticles can be synthesized using precipitation reactions in aqueous solutions. The discovery of metal-carbonyl complexes by thermolysis results in nanopowders.
\end{abstract}

Keyword: nanopowders, magnetic nanoparticles, simulation

\section{Introduction}

Magnetic nanoparticles, due to their mechanical, electrical and magnetic characteristics, high strength, safety, light weight, durability, reliability, corrosion resistance and low maintenance costs, have been the object of the researchers. Their wide scope includes [1,2,3].

1. shipbuilding-panels, ceilings, formworks, sanitary ware, decorations, furniture

2. naval transports: cargo-tanks, water and fuel tanks, containers, boats, hydroplanes, cooling installations, containers, structures consolidation, boat body construction, decks, etc

3.telecommunications-antennas, support elements and housings for radar, enclosures for cables

4. electrical installations - pallets of capacitors, motor stators, dials for circuits

5.cables for supporting and anchoring military bridges, as well as for elements of the structure of resistance, panels, tie rods for diagonal post-tensioning of marine platforms - polymer composites reinforced with fibers

6. Aeronautical, space and military applications

Due to the development of new preparation techniques, magnetic nanoparticles smaller than $10 \mathrm{~nm}$ in size, with narrow size distributions and different compositions can be manufactured by a variety of methods. 
Magnetic particles with nanometric dimensions have interesting properties that can be attributed either to the extrinsic properties of individual particles, such as finite size, or to surface effects and coupling between particles.

The fundamental understanding of the chemical, electrical, optical and magnetic properties of nanomaterials has been particularly important in the last two decades [2,4].

Magnetic nanoparticles represent a specific class of nanomaterials, composed of at least one magnetic element. These materials can be used in a variety of forms: in solution as ferrofluids for audio speakers, as aggregates of particles in magnetic storage media, as functionalized particles for biosensor applications, in the form of compact powders for energy generation or convection, in medical applications including targeted (magnetic) delivery of drugs and contrast agents in magnetic resonance imaging [4-29].

The study of the magnetic properties of nanomaterials is important for research in the field of nanoscience and nanotechnology.

Cobalt and iron have an internal energy level that is not completed, so that each metal atom has a permanent magnetic moment equal to power with the number of unpaired electrons [30].

\section{Methods of chemical synthesis of magnetic nanoparticles}

As with other types of inorganic materials, magnetic nanoparticles are obtained in such a way that they have controlled properties (by manipulating the processing parameters).

As methods of synthesis of magnetic nanoparticles we have: physical vapor deposition [31], mechanical (grinding) [32,33] and chemical synthesis in solution [34-37].

Mechanical nanostructures can be obtained by grinding alloys. The chemical methods of producing magnetic nanoparticles are preferred due to their high homogeneity at the molecular level, efficiency of production costs, control of particle size and particle size distribution, morphology and conglomerate size. Also, the modification of the surface is easy to perform, allowing the functionalization of the nanoparticles. Researcher Turkevich established the reproducible procedure for the preparation of the metal colloids and proposed the mechanism for the formation of nanoclusters, based on nucleation, growth and agglomeration $[38,39,40]$. Its model has been modified following the development of analytical techniques and thermodynamic and kinetic studies. According to this model, monodispersing is a consequence of the careful separation of the two stages: the nucleation stage and the subsequent growth stage.

For the metal particles, nucleation is the result of complex interactions between factors such as reaction conditions and the difference between the metal salt reduction potential and the reducing agent. The reaction conditions include the addition rate, the removal rate, the reaction temperature, the reaction time and even the stirring speed.

As a result of van der Waals forces and the tendency of the system to minimize the total surface energy, the nanostructured particles agglomerate. This can happen during synthesis (during the drying process), during handling and / or post-processing. Surfactants (any substance that influences the surface or interfacial tension of the environment in which it is dissolved) are used to prevent particle agglomeration to control dispersion during chemical synthesis, by reducing interactions between particles (by increasing repulsion forces). Stabilizing agents can also be used to control particle size and shape [41-44]. The chemical synthesis techniques used to form magnetic nanoparticles are shown in the diagram presented in figure $1[3]$.

Some techniques are used combinatorially or through a series of cross-field reactions. The dashed line indicates the demarcation between the syntheses using organic and aqueous solutions. Ground-gel and hydrothermal reactions lead to the production of oxide nanoparticles. This is due to the fact that the synthesis medium is an aqueous solution, without a source of reduction.

Many magnetic nanoparticles can be synthesized using precipitation reactions in aqueous solutions. These reactions can generate a wide range of magnetic materials, including ferrites with spinel or 
perovskite structure, metals and respectively metal alloys. Precipitation allows large quantities of particles to be obtained, but their size distribution is large.

In order to make the metal nanoparticles, different reactions are used. These reactions must take place under mild conditions (low temperatures), avoiding the formation of mixed oxide systems and for which a rigorous surface control can be performed.

The reduction of transition metal salts is the easiest and most widely used method for the preparation of metal nanoparticles. The most commonly used reducing agents are borohydride derivatives. This method provides an easy synthesis pathway for $\mathrm{Fe}$, Co and Ni nanoparticles, as well as for $\mathrm{Fe} / \mathrm{Pd}$ alloy, but has the disadvantage of including boron in particles that undergo a modification of the magnetic properties.

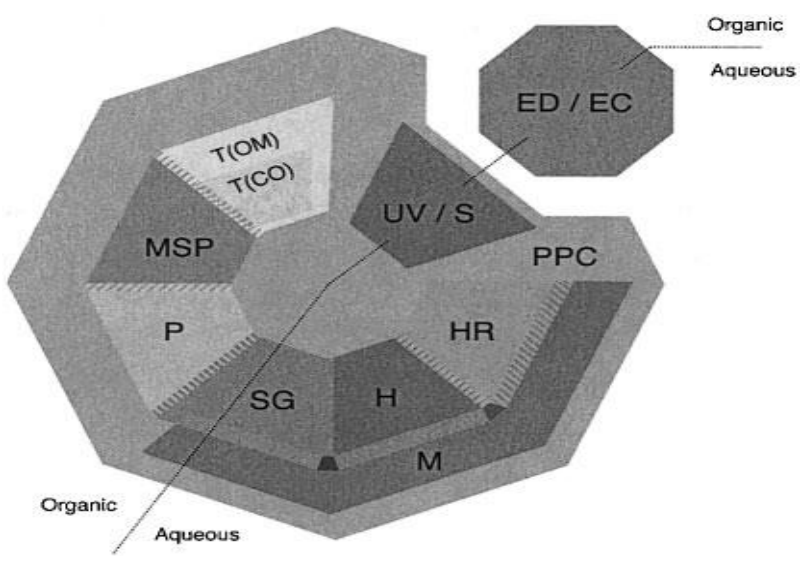

Figure 1. Schematic diagram of the chemical synthesis techniques used for the synthesis of magnetic nanoparticles, where: PPC: precipitation; H: hydrothermal; HR: reduction with hydride; M: microemulsion; $\mathrm{T}(\mathrm{OM})$ : thermolysis - decomposition of organometallic compounds; $\mathrm{T}(\mathrm{CO})$ : thermolysis - decomposition of carbonyl compounds; UV: photolysis; S: sonolysis; SG: ground - gel; P: polyol; EC: electrochemical; ED: electrodeposition; MSP: process made through a multitude of syntheses

The decomposition of metal-carbonyl complexes by thermolysis results in the production of nanopowders, nanostructured materials and nanoparticles in solution. The size and shape of which can be controlled by the reaction medium.

$\mathrm{Co}_{2}(\mathrm{CO})_{8}$ thermolysis of organo - metal compounds in solution, in the presence of trioctylphosphine oxide (TOPO) results in cobalt nanoparticles. Rapid thermolysis at high temperature $\left(1810^{\circ} \mathrm{C}\right)$ of the same precursor in the presence of organic molecules containing long alkyl chains and capable of serving as surfactants or ligands (oleic acid, phosphoric trioctyl acid or trioctylphosphine oxide) allows to obtain spherical monodisperse nanocrystals in the 3-17 $\mathrm{nm}$ range.

The decomposition of $\mathrm{Fe}(\mathrm{CO})_{5}$ by thermolysis results in obtaining metal nanoparticles whose size and shape can be controlled by the reaction medium. This process has recently been extended to the preparation of bimetallic and even trimetallic nanoparticles.

Metal-olefin compounds, by gentle decomposition in molecular hydrogen, lead to metal nanoparticles.

The method of microemulsion is to obtain a microemulsion of water in a nonpolar environment (eg: petroleum ether) using a non-ionic surfactant (eg poly-oxyethylene-nonyl phenol ether).

Even though the reaction rate is very high, no particle agglomeration occurs (if the stirring continues for several hours, flocculation phenomena may occur but the introduction into an ultrasonic bath allows the reduction to the original size).

Emulsions are dispersed systems consisting of two insoluble liquids one in the other, of which one is in a state of advanced dispersion. The dispersion of one liquid in the mass of another liquid can be 
affected by mechanical mixing. A liquid-liquid dispersed system cannot be called an emulsion unless it has a certain solubility. When emulsifying, the mechanical work spent increases the surface energy of the system. The higher the stored energy, the more unstable the emulsion, tending to shrink the surface of the system by joining the droplets as they come into contact due to the Brownian motion.

\section{Simulation of magnetic nanoparticles and their influence on the properties of the material}

For the first part, several two-dimensional numerical models were made using the FEMM program. It was considered a magnetostatic regime. In order to model the material, a square-shaped sample (side $=$ $0.1 \mu \mathrm{m}$ ) with particle inclusions (inclusion radius $=10 \mathrm{~nm}$ ) was considered - figure 2 . The sample was placed in a homogeneous field. In order to obtain this homogeneous field, the values of the magnetic vector potential on the borders were imposed.

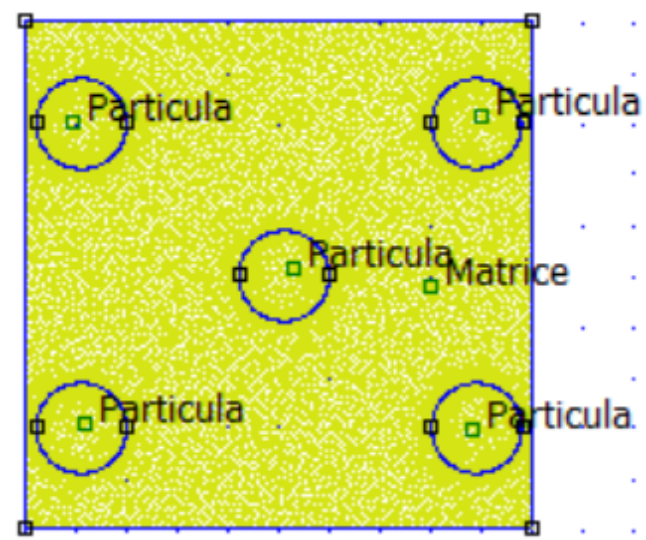

Figure 2. Problem geometry and mesh

The matrix is characterized by the relative magnetic permeability $\mu_{\mathrm{m}}=1$. For the inclusions, the permeability $\mu_{\mathrm{r}}=1000$ was considered. The presence of inclusions influences the lines of the magnetic field, and their concentration modifies the magnetic properties of the material. In general, the lower the concentration value, the higher the accuracy.

For the simulations two inclusion concentrations, $25 \%$ and $50 \%$, were considered. The analysis focused on the calculation of the induction of the magnetic field of the material for 2 cases: in the first case the number of inclusions was varied while the concentration was maintained constant, in the second case the position of the inclusions in the sample was varied.

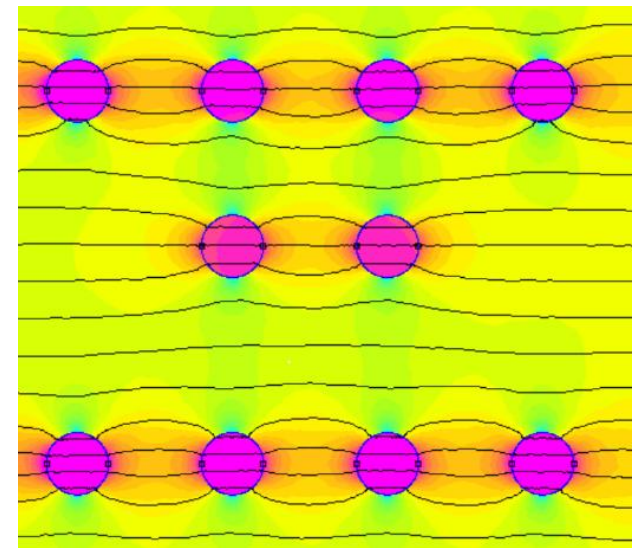

Figure 3. Magnetic field induction lines and color map 
Several points were considered. The magnetic induction values were calculated in each of these points. Of these values, in Table 1 are presented the values obtained in four points (close to the boundaries of the calculation domain) for the cases where the inclusions are centrally located.

\begin{tabular}{|l|r|r|r|r|r|}
\hline \multicolumn{7}{|c|}{ Table 1. Magnetic field induction values B[T] } \\
\hline & 1 particle & 2 particles & 5 particles & 10 particles \\
\hline P1 & 1.67 & 1.73 & 1.69 & 1.86 \\
\hline P2 & 2.4 & 2.33 & 2.33 & 2.02 \\
\hline P3 & 0.96 & 1.61 & 1.32 & 1.89 \\
\hline P4 & 1.6 & 1.73 & 1.69 & 1.89 \\
\hline
\end{tabular}

The differences between the induction values between the centrally placed and the randomly placed inclusions are about $9 \%$ if we have 2 particles and between $2 \%$ and 5\% if there are 5 particles. The differences are larger when the particles are placed on the edges. These differences are explained by the fact that when the particles are dispersed the interaction between the particles is minimal.

The 2D simulation was performed for a small number of particles. In the industrial field, nanopowders are successfully used for a lot of applications (electric machines, sensors, electromagnetic actuators, etc.), whether at low, medium or even high frequencies. The particles are in some cases covered with insulation, which should be perfect, which means that the turbulent currents should flow only inside the particles, with no other current paths. However, due to the pressing process, the insulating layer can be destroyed, which means that contacts can occur between the particles. These contacts influence losses through turbulent currents. For smaller samples of certain sizes, the losses through turbulent currents are due to the particles only, with no additional current paths. In contrast, if the sample sizes increase, macroscopic currents can no longer be neglected. This means that the losses through turbulent currents depend on the geometry of the samples - figure 4 [47].

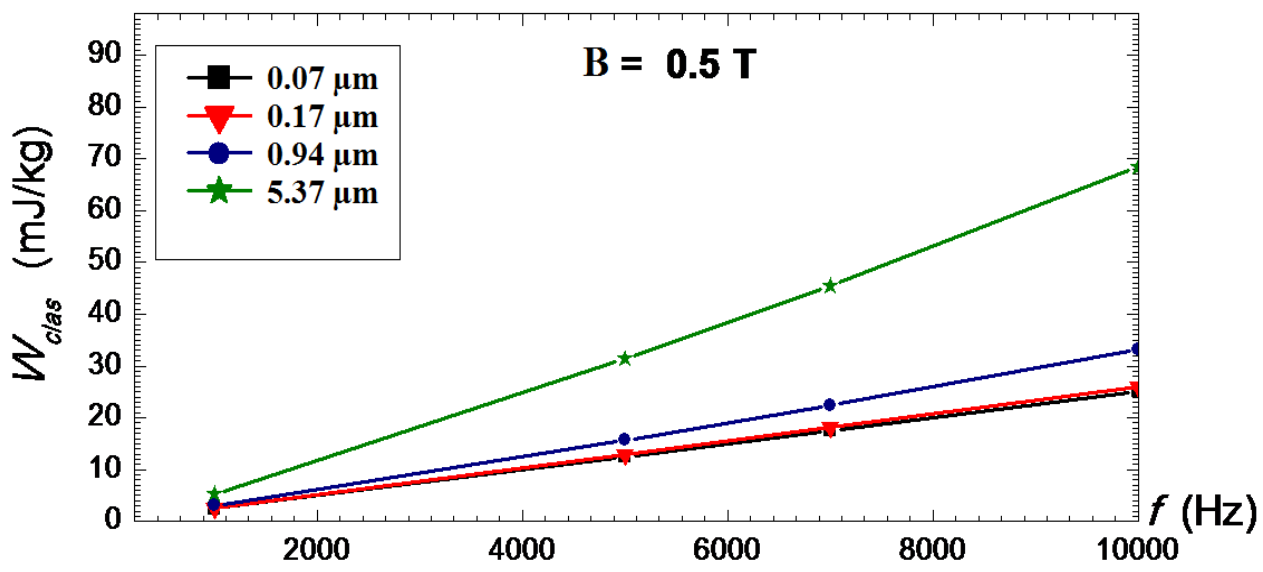

Figure 4. Classical losses Wclas dependency on the frequency f, for different contact lengths

It can be observed that for the small dimensions of the contact between the particles the differences between losses are almost indistinguishable. 


\section{Conclusions}

The solution synthesis offers several advantages: soft conditions, easier control of the particle size and composition, possibilities to modify the surface in order to obtain a stable dispersion in different solid or liquid mediums.

The particle size and their dispersion state determine the properties of nanometric powders, nanostructured materials and nanoparticles in solution. Following the analysis of the methods of synthesis of the nanometric magnetic particles, it was decided to perform laboratory syntheses through reactions in the liquid phase (reduction of the transition metal salts). For magnetic nanoparticles, which need to be incorporated into magneto-bioelectronic devices, chemical processing must control the composition, microstructure, phase purity and particle morphology as well as particle size control, thus reducing particle aggregation and size distribution.

\section{References}

[1] Hadjipanayis. G.C., Nanophase hard magnets, Magnetism and Magnetic Materials, 200, pp. 373-391, 1999

[2] Zamanpour M., Cobalt-based Magnetic Nanoparticles: Design, Synthesis and Characterization, Dissertation Northeastern University, Boston, 2014

[3] ***The Japan Marine Industry http://wtec.org/loyola/compce

[4] Willard M. A., Kurihara L.K., Carpenter E.E., Calvin S., Harris V.G., Chemically prepared magnetic nanoparticles, International materials reviews, 49, pp. 125- 170, 2004

[5] Sun S., C. B. Murray, D. Weller, L. Folks and A. Moser, Monodisperse FePt Nanoparticles and Ferromagnetic FePt Nanocrystal Superlattices, Science, 287, pp. 1989-1992, 2000

[6] R. D. K. Misra , T. Ha , Y. Kadman , C. J. Powell , M. D. Stiles , R. D. McMichael and W. E. Egclhoff, STM studies of GMR spin valves, MRS Proceeding, 384, pp.373 -383, 1995

[7] B. Chaudret, K. Philippot, Organometallic Nanoparticles of Metals or Metal Oxides, Oil \& Gas Science and Technology-Rev. IFP, Vol.62, No.6, pp. 799-817, 2007

[8] C. Meny , P. Panissod , P. Humbert, J. P. Nozienes, V. S. Speriosu , B. A. Gurney and R. Zehringer, Structural study of $\mathrm{Cu} / \mathrm{Co} / \mathrm{Cu} / \mathrm{NiFe} / \mathrm{FeMn}$ spin valves by nuclear magnetic resonance, Journal of Magnetism and Magnetic Materials, 121, pp.406 -408, 1993

[9] T. C. Huang , J. P. Nozieres , V. S. Speriosu , B. S. Gurney and H. Lefakis Effect of annealing on the interfaces of giant-magnetoresistance spin-valve structures, Applied Physics Letter, 62, pp.1478-1480, 1992

[10] S. Soeya , S. Tadokoro , T. Imagawa , M. Fuyama and S. Narishige, Magnetic-exchange coupling for bilayered $\mathrm{Ni} 81 \mathrm{fe} 19 / \mathrm{NiO}$ and trilayered Ni81Fe19/NiFeNb/NiO films, Journal of Applied Physics, 74, pp.6297 -6301, 1993

[11] W. F. Egelhoff Jr., P. J. Chen, C. J. Powell , M. D. Stiles , R. D. McMichael ,C.-L. Lin , J. M. Sivertsen, J. H. Judy, K. Takano and A. E. Berkowitz, The trade off between large GMR and small GMR and small coercivity in symmetric spin valves, Journal of Applied Physics, 79, pp.2491, 1996

[12] M. M. Miller, G. A. Prinz, S. F. Cheng and S. Bounnak, Detection of a micron sized magnetic sphere using a ring-shaped anisotropic magnetoresistance-based sensor: A model for a magnetoresistance-based, Applied Physics Letter, 81, pp. 2211-2214, 2002

[13] Blanc-Beguin F, Nabily S, Gieraltowski J, Turzo A, Querellou S, Salaun PY, Cytotoxicity and GMI bio-sensor detection of maghemite nanoparticles internalized into cells. Journal of Magnetism and Magnetic Materials, 321, 192-197, 2009

[14] Cavalli G, Banu S, Ranasinghe T, Broder GR, Martins HFP, Neylon C, Morgan H, Bradley M, Roach PL, Multistep synthesis on SU-8: combining microfabrication and solid-phase chemistry on a single material, Journal of Combined Chemistry, 9, 462-472, 2007

[15] Choi JW, Oh KW, Thomas JH, Heineman WR, Halsall HB, Nevin JH, Helmicki AJ, Henderson $\mathrm{HT}$, Ahn $\mathrm{CH}$, An integrated microfluidic biochemical detection system for protein analysis 
with magnetic bead-based sampling capabilities. Lab Chip 2, 27-30, 2002

[16] Golub TR, Slonim DK, Tamayo P, Huard C, Gaasenbeek M, Mesirov JP, Coller H, Loh ML, Downing JR, Caligiuri MA, Bloomfield CD, Lander ES, Molecular classification of cancer: class discovery and class prediction by gene expression monitoring, Science, 286, 531-537, 1999

[17] Graham DL, Ferreira HA, Bernardo J, Freitas PP, Cabral JMS, Single magnetic microsphere placement and detection on-chip using current line designs with integrated spin valve sensors: biotechnological applications. Journal of Applied Physics, 91, 7786-7788, 2003

[18] Togawa K, Sanbonsugi H, Sandhu A, Abe M, Narimatsu H, Nishio K, Handa H, High sensitivity InSb Hall effect biosensor platform for DNA detection and biomolecular recognition using functionalized magnetic nanobeads, Japanese Journal of Applied Physics, 44, 1494-1497, 2005

[19] Mihajlović G., K. Aledealat, P. Xiong, S. Molnár, M. Field and G. J. Sullivan, Magnetic characterization of a single superparamagnetic bead by phase-sensitive micro-Hall magnetometry, Applied Physics Letter, 91, pp. 172518-172521, 2007

[20] Shen W., L. C. Mathison, V. A. Petrenko and B. A. Chin, A pulse system for spectrum analysis of magnetoelastic biosensors, Applied Physics Letter, 96, pp. 163502-163505, 2010

[21] Gertz F., R. Azimov, and A. Khitun, Biological cell positioning and spatially selective destruction via magnetic nanoparticles, Applied Physics Letter, 101, pp. 013701-013704, 2012

[22] A.S. Lubbe, C. Bergemann, H. Riess, F. Schriever, P. Reichardt, K. Possinger, M. Matthias, B. Dorken, F. Herrmann, R. Gurtler, P. Hohenberger, N. Haas, R. Sohr, B. Sander, A.J. Lemke, D. Ohlendorf, W. Huhnt, D. Huhn, Clinical experiences with magnetic drug targeting: a phase I study with 4'-epidoxorubicin in 14 patients with advanced solid tumors, Cancer Research 56, pp. 4686-4693, 1996

[23] C. Zhang, B. Wangler, B. Morgenstern, H. Zentgraf, M. Eisenhut, H. Untenecker, R. Kruger, R. Huss, C. Seliger, W. Semmler, F. Kiessling, Silica- and alkoxysilanecoated ultrasmall superparamagnetic iron oxide particles: a promising tool to label cells for magnetic resonance imaging, Langmuir, 23, pp. 1427-1434, 2002

[24] R. Gref, M. Luck, P. Quellec, M. Marchand, E. Dellacherie, S. Harnisch, T. Blunk, R.H. Muller, 'Stealth' corona-core nanoparticles surface modified by polyethylene glycol (PEG): influences of the corona (PEG chain length and surface density) and of the core composition on phagocytic uptake and plasma protein adsorption, Colloids and Surfaces. B, Biointerfaces, 18, pp. 301-313, 2000

[25] M. Mikhaylova, Y.S. Jo, D.K. Kim, N. Bobrysheva, Y. Andersson, T. Eriksson, M. Osmolowsky, V. Semenov, M. Muhammed, The effect of biocompatible coating layers on magnetic properties of superparamagnetic iron oxide nanoparticles, Hyperfine Interactions, 156, pp. 257-263, 2004

[26] M. Veiseh, P. Gabikian, S.B. Bahrami, O. Veiseh, M. Zhang, R.C. Hackman, A.C. Ravanpay,M.R. Stroud, Y. Kusuma, S.J.Hansen, D.Kwok,N.M.Munoz, R.W. Sze,W.M. Grady, N.M. Greenberg, R.G. Ellenbogen, J.M. Olson, Tumor paint: a chlorotoxin: Cy5.5 bioconjugate for intraoperative visualization of cancer foci, Cancer Research, 67, pp.68826888,2007

[27] Glover P, Mansfield P. Limits to magnetic resonance microscopy. Reports on Progress in Physics 65, pp. 1489-1511, 2001

[28] M.E. Kooi, V.C. Cappendijk, K. Cleutjens, A.G.H. Kessels, P. Kitslaar, M. Borgers, P.M. Frederik, M. Daemen, J.M.A. van Engelshoven, Accumulation of ultrasmall superparamagnetic particles of iron oxide in human atherosclerotic plaques can be detected by in vivo magnetic resonance imaging, Circulation, 107, pp. 2453-2458, 2003

[29] R.A. Trivedi, J.M. U-King-Im, M.J. Graves, J.J. Cross, J. Horsley, M.J. Goddard, J.N. Skepper, G. Quartey, E.Warburton, I. Joubert, L.Q.Wang, P.J. Kirkpatrick, J. Brown, J.H. Gillard, In 
vivo detection of macrophages in human carotid atheroma - temporal dependence of ultrasmall superparamagnetic particles of iron oxideenhanced MRI, Stroke, 35, pp 16311635,2004

[30] K. Schulze, A. Koch, B. Schopf, A. Petri, B. Steitz, M. Chastellain, M. Hofmann, H. Hofmann, B. von Rechenberg, Intraarticular application of superparamagnetic nanoparticles and their uptake by synovial membrane - an experimental study in sheep, Journal of Magnetism and Magnetic Materials, 293, pp 419-432, 2004

[31] P. Varallyay, G. Nesbit, L.L. Muldoon, R.R. Nixon, J. Delashaw, J.I. Cohen, A. Petrillo, D. Rink, E.A. Neuwelt, Comparison of two superparamagnetic viral sized iron oxide particles ferumoxides and ferumoxtran-10 with a gadolinium chelate in imaging intracranial tumors, American Journal of Neuroradiology, 23, pp 510-519, 2002

[32] Carroll K, Core-shell Nanoparticles: Synthesis, Design, and Characterization, Ph.D. Dissertation, Virginia Commonwealth University, 2007

[33] Moreau N, C. Michiels, B. Masereel, O. Feron, B. Gallez, T. V. Borght and S. Lucas, PVD Synthesis and Transfer into Water-Based Solutions of Functionalized Gold Nanoparticles, Plasma Processes and Polymers, 6, pp. 888-892, 2009

[34] Shi Y., J. Ding, X. Liu, J. Wang, NiFe2O4 ultrafine particles prepared by coprecipitation/mechanical alloying, Magnetism and Magnetic Materials, 205, pp. 249-254, 1999

[35] Zhiqiang J., W. Tang, J. Zhang, H. Lin, Y. Du., Magnetic properties of isotropic SrFe12O19 fine particles prepared by mechanical alloying, Magnetism and Magnetic Materials, 182, pp. 231-237, 1998

[36] Chen J. and D. E. Nikles, Preparation of acicular $\alpha$-Fe nanoparticles in a lamellar liquid crystalline phase, IEEE Transactions on Magnetics, 32, pp. 4478-4480, 1996

[37] Chen M., B. Tang and D. E. Nikles, Preparation of iron nanoparticles by reduction of acicular $\beta$ FeOOH particles, IEEE Transactions on Magnetics, 34, pp. 1141-1176, 1998

[38] Krehula S., S. Popovic and S. Music, Synthesis of acicular $\alpha$-FeOOH particles at a very high pH, Materials Letter, 54, pp. 108-113, 2002

[39] Chakroune N., G. Viau, C. Ricolleau, F. Fievet-Vincent and F. Fievet, Cobalt based anisotropic particles prepared by the polyol process, Materials Chemistry, 13, pp. 312-318, 2003

[40] Turkevich J., P. C. Stevenson, J. Hillier, A study of the nucleation and growth processes in the synthesis of colloidal gold, Discussions of the Faraday Society, 11, pp. 55-57, 1951

[41] Turkevich J., G. Kim, Palladium: preparation and catalytic properties of particles of uniform size, Science 169, pp.873-875, 1970

[42] Turkevich J., Nucleation and Growth Process in the Synthesis of Colloidal Gold, Gold Bulletin, 18, pp. 86-88, 1985

[43] Peng X., L. Manna, W. Yang, J. Wickham, E. Scher, A. Kadavanich and A. P. Alivisatos, Shape control of CdSe nanocrystals, Nature, 404, pp. 59-61, 2000

[44] Murray B. C., C. R. Kagan, M. G. Bawendi, Synthesis and characterization of monodisperse nanocrystals and close-packed nanocrystals assemblies, Annual Review of Materials Science, 30, pp. 545-610, 2000

[45] LaMer V. K. and M.D. Barnes, Theory, Production and mechanism of formation of monodispersed hydrosols, Journal of Colloidal Science, 1, pp. 71-77, 1946

[46] Lalena, J. N., D. A. Cleary, E. E. Carpenter, N. F. Dean, Inorganic Materials Synthesis and Fabrication; John Wiley \& Sons: New Jersey, pp. 41-70, 2008

[47] Bordianu A, Modelarea proprietatilor magnetice ale materialelor compozite, $\mathrm{PhD}$ thesis, University Politehnica of Bucharest, Romania 